\title{
TES CRAAP SEBAGAI INDIKATOR EVALUASI INFORMASI
}

\author{
Nita Siti Mudawamah \\ Program Studi Perpustakaan dan Ilmu Informasi, Fakultas Sains dan Teknologi \\ UIN Maulana Malik Ibrahim Malang \\ nitastmudawamah@uin-malang.ac.id
}

\begin{abstract}
Abstrak - Evaluasi informasi merupakan salah satu elemen standar dalam literasi informasi. Tes CRAAP menjadi salah satu cara untuk mengevaluasi informasi, mengidentifikasi informasi dan menilai keabsahan informasi. Kriteria yang terdapat dalam CRAAP ini banyak digunakan untuk menilai informasi yang terdapat dalam situs web sehingga informasi palsu atau pun berita bohong akan mudah diidentifikasi. Dengan adanya kemampuan dalam menerapkan tes CRAAP ini pada akhirnya masyarakat akan dapat menentukan mana informasi yang layak untuk digunakan mana informasi yang tidak perlu digunakan. Tulisan ini merupakan sebuah artikel konseptual. Metode yang digunakan dalam tulisan ini adalah studi pustaka yang dipilih berdasarkan sumber informasi yang relevan. Penulis mengumpulkan data dan informasi menggunakan beragam sumber referensi diantaranya buku, jurnal ilmiah, serta situs web yang dinilai kredibel. Tulisan ini akan mendeskripsikan bagaimana cara mengevaluasi informasi dengan kriteria Tes CRAAP (Currency, Relevance, Authority, Accuracy, Purpose).
\end{abstract}

\section{Kata kunci: Evaluasi Informasi, Tes CRAAP, Literasi Informasi}

\section{Pendahuluan}

Sebuah fakta yang menarik telah dingkapkan oleh Duby (2018) seorang Library Director untuk Sullivan County Public Library System. Menurutnya meski saat ini orang-orang cenderung mencari informasi melalui google daripada memilih perpustakaan, tetapi masih ada orang-orang bertanya kepada pustakawan mengenai keabsahan informasi yang telah mereka dapatkan dari koran, media sosial, maupun situs berita. Melihat fenomena tersebut, pustakawan tentunya sangat berperan untuk membantu para pemustaka dalam mengevaluasi informasi sehingga mereka mendapatkan informasi yang berkualitas. Sebenarnya kemampuan mengevaluasi informasi adalah sebuah keniscayaan yang harus dimiliki oleh setiap orang. Para siswa mulai dari pendidikan dasar hingga pendidikan tinggi perlu dibekali dengan kemampuan ini untuk menghindari efek negatif karena keberlimpahan informasi.

Evaluasi informasi merupakan salah satu elemen standar dalam literasi informasi. Model literasi informasi Seven Pillars mencantumkan secara eksplisit mengenai kemampuan evaluasi informasi bersamaan dengan standar yang lainnya. Standar literasi informasi yang dirumuskan oleh Society of College, National and University Libraries/ SCONUL (2011) ini antara lain manage, evaluate, present, gather, identify, dan scope. Standar evaluasi pada model ini merupakan kemampuan untuk dapat mereview sebuah proses penelitian serta mampu untuk membandingkan informasi yang didapatkan juga 
mampu memilih informasi yang berkualitas tanpa adanya bias. Tulisan ini akan mendeskripsikan bagaimana cara mengevaluasi informasi dengan kriteria Tes CRAAP (Currency, Relevance, Authority, Accuracy, Purpose).

\section{Tinjauan Pustaka}

Topik menganai evaluasi informasi menggunakan Tes CRAAP telah ditulis oleh beberapa peneliti. Pertama, penelitian yang ditulis oleh Sarah Myhre berjudul "Using CRAAP Test to Evaluate Websites". Dalam penelitiannya Myhre membuat modul penggunaan CRAAP untuk diuji coba pada mahasiswa di University of Hawai System. Modul tersebut dibuat sebagai sarana untuk mengajar mahasiswa dalam mengevaluasi situs web. Hasil dari uji coba tersebut menunjukkan adanya peningkatan pemahaman mahasiswa mengenai evaluasi situs web (Myhre, 2012).

Kedua, kajian yang dilakukan oleh Abbey B. Lewis dalam tulisannya yang berjudul "What Does Bad Information Look Like? Using the CRAAP Test for Evaluating Substandard Resources". Dalam tulisannya Lewis (2018) mendeskripsikan aktivitas para mahasiswa dalam menilai kualitas informasi yang akan digunakan untuk tugas akademik. Mahasiswa dibagi atas lima kelompok sesuai dengan jumlah kiteria dalam Tes CRAAP, setiap kelompok harus mampu menjawab pertanyaan yang terdapat pada masing-masing kriteria serta memaparkan hasil pengamatannya. Hasil dari aktivitas tersebut menunjukkan bahwa seluruh mahasiswa mampu menerapkan Tes CRAAP meskipun masih ada beberapa kebingungan dalam penerapannya, hal ini disebabkan oleh adanya konsep evaluasi dalam Tes CRAAP yang dinilai kurang jelas.

Kedua tinjauan pustaka tersebut memiliki persamaan serta perbedaan dengan tulisan ini. Persamaanya, tulisan ini akan membahas mengenai penggunaan tes CRAAP sebagai alat ukur evaluasi informasi namun ditulis berupa artikel konseptual.

\section{Metode Penelitian}

Metode yang digunakan dalam tulisan ini adalah studi pustaka yang dipilih berdasarkan sumber informasi yang relevan. Penulis mengumpulkan data dan informasi menggunakan beragam sumber referensi diantaranya buku, jurnal ilmiah, serta situs web yang dinilai kredibel. Data dan informasi yang telah dikumpulkan akan ditelaah hingga menjadi sebuah tulisan konseptual.

\section{Hasil dan Pembahasan}




\section{A. Pentingnya Evaluasi Informasi}

Kehadiran internet adalah salah satu bentuk pencapaian besar umat manusia yang berimbas ke segala aspek kehidupan. Tatatan nilai, moral, sosial, budaya menjadi berubah. Konsep eksistensi manusia juga menjadi berubah. Jumlah informasi di internet tidak terbatas lagi, satu kata kunci yang diketik di mesin mencari bisa menghasilkan puluhan juta informasi yang mengandung kata kunci yang sama. Nichols (2018) mengungkapkan besarnya ukuran dan volume internet, serta ketidakmampuannya memisahkan pengetahuan yang bermakna dari keributan acak, menyebabkan informasi yang baik akan selalu dirubung informasi yang buruk dan aneh. Meski begitu, internet masih menyediakan jutaan informasi yang bagus, berita yang bermutu, publikasi hasil penelitian. Yang menjadi masalah adalah kita harus bisa menemukan informasi yang bermutu di antara sekian juta informasi yang tidak berguna. Inilah yang menjadi alasan pentingya seseorang untuk memiliki kemampuan evaluasi informasi.

Kemampuan evaluasi informasi sebenarnya menjadi sebuah keterampilan yang ditetapkan oleh SCONUL (2011) dalam menilai kemampuan literasi informasi seseorang. Kegiatan literasi informasi menjadi sebuah kegiatan utama di perpustakaan. Para pustakawan khususnya di perguruan tinggi secara konsisten telah mengajarkan kemampuan literasi informasi bagi mahasiswa maupun dosen. Sebenarnya, kegiatan literasi informasi bisa diterapkan ke lapisan masyarakat secara umum agar tercipta sebuah tatanan masyarakat yang terpelajar hal ini sesuai laporan yang disampaikan ALA (1989) bahwa seseorang yang menerapkan literasi informasi adalah orang yang belajar bagaimana belajar. Indikator bahwa seseorang memiliki keterampilan evaluasi dijabarkan dalam pilar kelima pada Model Seven Pillars (2011), indikator tersebut yaitu:

1. Memahami kerangka penggunaan informasi untuk pembelajaran dan penelitian

2. Memahami kualitas, ketepatan, relevansi, bias, reputasi, dan kredibilitas sumber informasi

3. Memahami bagaimana informasi dievaluasi dan dipublikasikan

4. Memahami pentingnya pengumpulan data secara konsisten

5. Memahami pentinya pengutipan dalam pembelajaran maupun penelitian

6. Mampu memilih informasi sesuai dengan topik yang diinginkan

7. Mampu menilai kualitasi, ketepatan, relevansi, bias, dan kredibilitas sumber informasi yang ditemukan

8. Mampu menilai kredibilitas data yang telah dikumpulkan

9. Mampu membaca secara kritis, dan mengidentifikasi gagasan utama

10. Mampu mencocokkan informasi yang ditemukan dengan strategi pencarian yang digunakan 
11. Mampu menilai dan mengevaluasi hasil temuan penelitian yang dihasilkan oleh diri sendiri maupun orang lain

12. Mampu mengetahui kapan harus berhenti

\section{B. Mengenal Tes CRAAP}

Munculnya akronim CRAAP bermula ketika Sarah Blakeslee yang merupakan seorang pustakawan di Meriam Library California State University, Chico mengembangkan lokakarya untuk melatih para instruktur literasi informasi. Ia merasa harus menemukan istilah yang tepat untuk setiap kriteria evaluasi sumber informasi yang dilakukan pada sesi pelatihan. Evaluasi informasi merupakan keterampilan bagi para pustakawan untuk mengajari pemustaka dalam memilih sumber informasi yang berkualitas dan terpercaya. Blakeslee mengungkapkan ketika ia mengajari cara mengevaluasi informasi kepada para siswa tentunya ia harus mengingat seluruh kiteria dalam evaluasi tersebut agar para siswa juga dapat mengingatnya (Blakeslee, 2004). Atas dasar pentingnya evaluasi informasi akhirnya muncul lima kata kunci atau kriteria yang masing-masing mengandung pertanyaan yang harus ditanyakan ketika seseorang ingin mencari informasi sampai pada tahap mendapatkan informasi. Lima kriteria tersebut antara lain: Currency, Relevance, Authority, Accuracy, Purpose (Meriam Library - California State University Chico, 2015). Blakeslee (2004) menyusun kelima kriteria tersebut menjadi sebuah akronim, yaitu CRAAP. Penggunaan akronim ini ternyata menarik perhatian para siswa selama kuliah, penyampaian materi pun menjadi menyenangkan. Hal ini berimbas pada peningkatan pemahaman para siswa dalam mengingat kriteria evaluasi informasi.

Metode Tes CRAAP ini juga telah dimodifikasi di antaranya oleh Laura Karas dan para pustakawan di University of South Carolina Upstate. Modifikasinya telah menghasilkan metode STAAR yang juga digunakan untuk mengevaluasi situs web. STAAR merupakan akronim dari Slant, Topical and Timely, Authority, Accuracy, dan Relevance (Karas, n.d.).

\section{Kriteria Evaluasi Informasi Menggunakan Tes CRAAP}

Tes CRAAP menjadi salah satu cara untuk mengidentifikasi informasi, ini menjadi sebuah alat ukur untuk menilai keabsahan informasi. Kriteria yang terdapat dalam CRAAP ini banyak digunakan untuk menilai informasi yang terdapat dalam situs web sehingga informasi palsu atau pun berita bohong akan mudah diidentifikasi. Dengan adanya kemampuan dalam menerapkan tes CRAAP ini pada akhirnya masyarakat akan dapat menentukan mana informasi yang layak untuk digunakan mana informasi yang 
tidak perlu digunakan. Hal tentunya akan berakibat pada perubahan pola perilaku pencarian informasi masyarakat. Kriteria tes CRAAP ini meliputi:

1. Currency/Kebaruan

Keandalan sebuah informasi dapat dilihat dari kapan informasi itu dipublikasikan. Informasi yang andal adalah informasi yang terkini. Perlunya memilih informasi yang terkini tidak terlepas dari pertambahan serta perubahan informasi setiap waktu. Kriteria kebaruan terlihat dari kapan waktu informasi dipublikasikan, apakah ada konten yang direvisi atau diperbarui, apakah informasi relevan dengan topik yang sedang dicari, apakah tautan informasi dapat berfungsi.

2. Relevance/Relevansi:

Kriteria relevansi ini mengacu pada kesesuaian antara informasi yang didapatkan dengan kebutuhan informasi. Kriteria ini dapat dilihat dari beberapa indikator antara lain apakah informasi yang didapatkan dapat menjawab pertanyaan, siapa sasaran penerima informasi, apakah level informasi seusuai dengan kebutuhan.

\section{Authority/ Otoritas:}

Kriteria ini dapat mengidentifikasi pihak-pihak yang berada dibalik informasi yang sedang kita abaca. Informasi yang terpercaya adalah informasi yang dapat dipertanggungjwabkan, dapat diverifikasi, penulisnya tertulis dengan jelas tidak anonim, informasi ditulis oleh seseorang yang memiliki kualifikasi di bidangya. Untuk mengetahui informasi lebih lanjut mengenai pihak-pihak yang terlibat, bisa mengunjungi laman "About Us" pada setiap situs web yang dikunjungi. Apabila indikator tersebut dapat ditemukan dalam laman situs web berarti informasi tersebut memiliki kredibilitas.

\section{Accuracy/ Penyajian konten secara benar}

Kriteria ini bisa dilihat dari dua sisi, pertama dari cara penulisan, kedua dari sisi konten tulisan. Ciri-ciri informasi terpercaya ialah adanya ketepatan dalam pembuatannya, sumbernya tertera dengan jelas, sumber referensi yang digunakan dapat diverifikasi dan ditelusuri, bahasa informasi yang digunakan bebas emosi dan juga tidak bias, tidak terdapat kesalahan ejaan atau kesalahan tata bahasa.

\section{Purpose/Tujuan pembuatan informasi}

Adanya kriteria ini bertujuan untuk membantu pembaca mengetahui apakah informasi yang didapatkan sudah sesuai dengan kebutuhan mereka. Beberapa pertanyaan yang muncul untuk mengetahui mengidentifikasi kriteria ini meliputi apakah informasinya bertujuan untuk edukasi atau hiburan atau berjualan? Apakah tujuan tersebut tertulis dengan jelas dalam informasi yang ditampilkan? Apakah informasinya mengandung fakta atau asumsi atau propaganda? Siapa yang 
mendapat keuntungan dari adanya informasi? Apakah informasinya memihak pihak tertentu? Apakah informasinya mengandung bias politik/ideologi/budaya/agama?

Berikut merupakan kriteria evaluasi informasi dengan menggunakan metode Tes CRAAP yang tergambar melalui tabel:

Table 1 Kriteria Evaluasi Informasi

\begin{tabular}{|c|c|c|}
\hline No & Kriteria & Indikator \\
\hline 1 & Currency & $\begin{array}{l}\text { a. Kapan informasi dipublikasikan/diposting? } \\
\text { b. Apakah terdapat revisi atau pembaharuan pada informasi yang telah } \\
\text { dipublikasikan? } \\
\text { c. Apakah informasinya terkini atau sudah out-of date untuk topik anda? } \\
\text { d. Apakah tautannya berfungsi/dapat diklik? }\end{array}$ \\
\hline 2 & Relevance: & $\begin{array}{l}\text { a. Apakah informasi tersebut berkaitan dengan topik Anda? Apakah informasinya } \\
\text { menjawab pertanyaan Anda? } \\
\text { b. Informasi tersebut ditujukan untuk siapa? } \\
\text { c. Apakah level informasinya sesuai dengan kebutuhan? (tidak terlalu basic/tidak } \\
\text { terlalu advance) } \\
\text { d. Pernahkah Anda membaca terlebih dulu beragam sumber informasi sebelum } \\
\text { menentukan sumber mana yang akan digunakan? } \\
\text { e. Apakah Anda merasa nyaman menggunakan sumber tersebut untuk makalah } \\
\text { penelitian/tugas? }\end{array}$ \\
\hline 3 & Authority: & $\begin{array}{l}\text { a. Siapakah penulis / penerbit / sumber / sponsor? } \\
\text { b. Apa penulis tergabung dalam organisasi, perusahaan atau lembaga terterntu? } \\
\text { c. Apakah penulis memiliki kualifikasi sesuai dengan topik tulisannya? } \\
\text { d. Apakah penulis bisa diverifikasi? } \\
\text { e. Apakah ada informasi yang dapat dihubungi, seperti penerbit atau alamat } \\
\text { email? } \\
\text { f. Apakah Anda dapat menemukan informasi tentang penulis melalui situs lain? }\end{array}$ \\
\hline 4 & Accuracy: & $\begin{array}{l}\text { a. Darimana informasi itu berasal? } \\
\text { b. Apakah informasinya didukung oleh bukti? } \\
\text { c. Apakah informasi telah melalui proses peninjauan dan proses edit? } \\
\text { d. Apakah sumber referensi yang digunakan bisa ditelusuri dan diverifikasi? } \\
\text { e. Apakah bahasa yang digunakan mengandung bias dan bebas emosi? } \\
\text { f. Apakah ada kesalahan ejaan, atau kesalahan bahasa? }\end{array}$ \\
\hline
\end{tabular}




\begin{tabular}{|l|l|l|l|}
\hline & & a. Apa tujuan informasi tersebut? Apakah untuk edukasi, hiburan, atau jualan? \\
& & b. Apakah penulis / organisasi menjelaskan maksud atau tujuannya? \\
& c. Apakah informasi itu berupa fakta, pendapat atau propaganda? \\
& & $\begin{array}{l}\text { d. Siapa yang mendapatkan keuntungan dari adanya informasi tersebut? } \\
\text { e. Apakah informasinya memihak pihak tertentu? }\end{array}$ \\
& Adakah informasinya mengandung bias politik, ideologis, budaya, agama, \\
\hline
\end{tabular}

Sumber: Meriam Library - California State University Chico, 2015

Tim dari Ron E Lewis Library juga telah melakukan modifikasi pada Tes CRAAP dengan menambahkan beberapa poin untuk masing-masing kriteria. Mereka juga telah membuat alat uji yang berbentuk scorring agar peniliannya lebih terukur. Berikut kriteria CRAAP yang diadopsi oleh Ron E Lewis Library:

Tabel 2. Kriteria Tes CRAAP yang diadopsi oleh Ron E Lewis Library

\begin{tabular}{|c|c|c|c|c|}
\hline $\begin{array}{c}\text { Checking for } \\
\text { CRAAP }\end{array}$ & Poin: 0 & 1 & 2 & 3 \\
\hline Currency & $\begin{array}{l}\text { Tidak ada } \\
\text { keterangan yang } \\
\text { menunjukkan } \\
\text { kapan situs web } \\
\text { dibuat atau } \\
\text { diperbarui }\end{array}$ & $\begin{array}{l}\text { Situs web dibuat } \\
\text { lebih dari } 5 \text { tahun } \\
\text { tetapi tidak ada } \\
\text { keterangan tanggal } \\
\text { dan waktu } \\
\text { pembaruan }\end{array}$ & $\begin{array}{l}\text { Situs web dibuat, } \\
\text { direvisi atau } \\
\text { diperbarui dalam } \\
5 \text { tahun terakhir. } \\
\text { Sumber referensi } \\
\text { memakai sumber } \\
\text { terbaru }\end{array}$ & $\begin{array}{l}\text { Situs web dibuat, } \\
\text { direvisi atau } \\
\text { diperbarui dalam } \\
2 \text { tahun terakhir. } \\
\text { Sumber referensi } \\
\text { memakai sumber } \\
\text { terbaru }\end{array}$ \\
\hline Relevance & $\begin{array}{l}\text { Informasi pada } \\
\text { situs web tidak } \\
\text { sesuai atau bahkan } \\
\text { terlalu singkat } \\
\text { sehingga tidak } \\
\text { cukup memenuhi } \\
\text { kebutuhan } \\
\text { informasi Anda }\end{array}$ & $\begin{array}{l}\text { Situs web } \\
\text { memberikan } \\
\text { beberapa } \\
\text { informasi tetapi } \\
\text { tidak cukup } \\
\text { memenuhi } \\
\text { kebutuhan } \\
\text { informasi Anda, } \\
\text { atau jenis } \\
\text { informasi tidak } \\
\text { sesuai. }\end{array}$ & $\begin{array}{l}\text { Situs web } \\
\text { memberikan } \\
\text { cukup banyak } \\
\text { informasi sesuai } \\
\text { kebutuhan Anda, } \\
\text { tetapi Anda masih } \\
\text { membutuhkan } \\
\text { lebih banyak } \\
\text { informasi lain. }\end{array}$ & $\begin{array}{l}\text { Situs web memuat } \\
\text { topik, jumlah, dan } \\
\text { informasi yang } \\
\text { tepat sesuai } \\
\text { kebutuhan Anda }\end{array}$ \\
\hline Authority & $\begin{array}{l}\text { Situs web tidak } \\
\text { mencantumkan } \\
\text { nama } \\
\text { penulis/kontributor, } \\
\text { organisasi tidak } \\
\text { terkenal, terdapat } \\
\text { kesalahan teks }\end{array}$ & $\begin{array}{l}\text { Situs web } \\
\text { mencantumkan } \\
\text { nama } \\
\text { penulis/kontributor } \\
\text { tanpa keterangan } \\
\text { keahlian . } \\
\text { Otoritas organisasi }\end{array}$ & $\begin{array}{l}\text { Situs we } \\
\text { mencantumkan } \\
\text { nama penulis, } \\
\text { tetapi kemampuan } \\
\text { penulis tersebut } \\
\text { kurang kompeten } \\
\text { di bidangnya }\end{array}$ & $\begin{array}{l}\text { Nama penulis } \\
\text { serta keahliannya } \\
\text { tertera sangat jelas } \\
\text { dalam situs web. } \\
\text { Organisasi sudah } \\
\text { terkenal dan } \\
\text { sangat kredibel }\end{array}$ \\
\hline
\end{tabular}




\begin{tabular}{|c|c|c|c|c|}
\hline & & $\begin{array}{l}\text { patut } \\
\text { dipertanyakan. } \\
\text { Terkadang nama } \\
\text { organisasi dibuat } \\
\text { mirip dengan } \\
\text { organisasi yang } \\
\text { sudah memiliki } \\
\text { kredibilitas }\end{array}$ & $\begin{array}{l}\text { Situs web } \\
\text { mencantumkan } \\
\text { nama organisasi } \\
\text { tetapi bidang } \\
\text { kajiannya tidak } \\
\text { tercantum dengan } \\
\text { jelas }\end{array}$ & \\
\hline Accuracy & $\begin{array}{l}\text { Tidak ada sumber } \\
\text { referensi yang } \\
\text { dipakai }\end{array}$ & $\begin{array}{l}\text { Sumber referensi } \\
\text { yang digunakan } \\
\text { tidak jelas. } \\
\text { Sumbernya } \\
\text { berdasarkan } \\
\text { asumsi }\end{array}$ & $\begin{array}{l}\text { Sumber referensi } \\
\text { tertera, namun } \\
\text { tidak dapat } \\
\text { ditelusuri }\end{array}$ & $\begin{array}{l}\text { Sumber informasi } \\
\text { sangat jelas dan } \\
\text { dapat ditemukan. } \\
\text { Gambar/foto } \\
\text { diberi keterangan } \\
\text { serta sumbernya }\end{array}$ \\
\hline Purpose & $\begin{array}{l}\text { Sudut pandang } \\
\text { yang bias, menjual } \\
\text { atau } \\
\text { mempromosikan } \\
\text { ide, layanan, atau } \\
\text { produk. } \\
\text { Sudut pandang } \\
\text { yang tidak faktual } \\
\text { atau tidak } \\
\text { seimbang. } \\
\text { Pendapat tidak } \\
\text { didukung oleh } \\
\text { fakta atau fakta } \\
\text { yang menyimpang. }\end{array}$ & $\begin{array}{l}\text { Situs web } \\
\text { bertujuan untuk } \\
\text { menjual atau } \\
\text { mempromosikan } \\
\text { sesuatu, tetapi juga } \\
\text { menyediakan } \\
\text { beberapa } \\
\text { informasi faktual } \\
\text { yang baik. Atau } \\
\text { pendapat yang } \\
\text { diungkapkan } \\
\text { cukup logis dan } \\
\text { menyertakan } \\
\text { beberapa bukti. }\end{array}$ & $\begin{array}{l}\text { Situs web } \\
\text { bertujuan } \\
\text { memberikan } \\
\text { informasi faktual. } \\
\text { Pendapat } \\
\text { diungkapkan } \\
\text { secara logis } \\
\text { disertai dengan } \\
\text { sumber yang } \\
\text { cukup. }\end{array}$ & $\begin{array}{l}\text { Situs web } \\
\text { memberikan } \\
\text { informasi ilmiah } \\
\text { atau informasi } \\
\text { berkualitas } \\
\text { berkualitas. Bukti } \\
\text { pendapat bersifat } \\
\text { faktual, disajikan } \\
\text { dalam bentuk } \\
\text { angka dalam } \\
\text { bagan, grafik, } \\
\text { tabel, atau statistik } \\
\text { atau bukti yang } \\
\text { relevan dengan } \\
\text { pendapat tersebut. }\end{array}$ \\
\hline Total Skor: & $\begin{array}{c}\text { 0 sampai } 3 \text { poin } \\
\text { Sumber sangat } \\
\text { dipertanyakan. } \\
\text { Jangan gunakan. }\end{array}$ & $\begin{array}{c}4 \text { hingga } 7 \text { poin } \\
\text { boleh dibaca saja } \\
\text { tetapi jangan } \\
\text { dikutip }\end{array}$ & $\begin{array}{c}8 \text { sampai } 11 \\
\text { Sumber yang } \\
\text { baik untuk } \\
\text { digunakan dan } \\
\text { dikutip. } \\
\end{array}$ & $\begin{array}{c}12 \text { sampai } 15 \\
\text { Sumber yang } \\
\text { sangat bagus } \\
\text { untuk digunakan } \\
\text { dan dikutip. } \\
\end{array}$ \\
\hline
\end{tabular}

Sumber: (Ron E. Lewis Library, n.d.)

\section{Kesimpulan}

Tes CRAAP yang merupakan sebuah akronim dari Currency, Relevance, Authority, Accuracy, Purpose merupakan kriteria yang sangat berguna untuk menilai keabsahan sebuah sumber informasi yang terdapat dalam situs web. Tes CRAAP ini dapat digunakan oleh siapapun. Penerapan tes ini menjadi cara untuk melatih seseorang berpikir kritis ketika membaca informasi, sehingga dapat terhindar dari 
informasi salah dan juga berita palsu. Penerapan tes ini juga menjadi tolak ukur untuk mengetahui kemampuan literasi informasi.

\section{Daftar Pustaka}

American Library Association. (1989). Presidential Committee on Information Literacy: Final Report. https://libguides.ala.org/InformationEvaluation/Infolit

Bent, M., \& Stubbings, R. (2011). The SCONUL Seven Pillars of Information Literacy: Core Model For Higher Education. In SCONUL Wprking Group on Information Literacy. https://doi.org/10.1108/00907320610716486

Blakeslee, S. (2004). The CRAAP Test Library Services for International Students. 31, 6-7.

Duby, H. R. (2018). What a Load of CRAAP: Evaluating Information in an Era of "Fake News". Tennessee Libraries, 68(4), 4. http://eresources.perpusnas.go.id:2048/login?url=http://search.ebscohost.com/login.aspx?direct=true \&db=li h\&AN=134318248\&site $=$ eds-live

Karas, L. (n.d.). Is your website a S.T.A.A.R.? 5. https://uscupstate.libguides.com/c.php?g=257977\&p=1721754

Lewis, A. B. (2018). What Does Bad Information Look Like? Using the CRAAP Test for Evaluating Substandard Resources. Issues in Science \& Technology Librarianship. https://doi.org/10.5062/f41n7zc4

Meriam Library - California State University Chico. (2015). Evaluating Information - Applying the CRAAP Test. 17. https://www.csuchico.edu/lins/handouts/eval_websites.pdf

Myhre, S. (2012). Using the CRAAP Test to Evaluate Websites. http://hdl.handle.net/10125/22479

Nichols, T. (2018). Matinya Kepakaran. Kepustakaan Populer Gramedia.

Ron E. Lewis Library. (n.d.). Thinking Critically about Web Information-Applying the CRAAP Test. Lamar State College Orange. http://library.lsco.edu/help/web-page-rubric.pdf 